\title{
Family Reunions: Visionary Encounters with the Departed in a Modern-Day Psychomanteum
}

\author{
Raymond A. Moody, Jr., Ph.D., M.D. \\ Anniston, $A L$
}

ABSTRACT: A poignant feature of many near-death experiences is a visionary encounter with deceased loved ones. Over the centuries, researchers have sought safe ways to replicate near-death and related experiences, hoping to induce the powerful aftereffects of these events. The ancient Greeks contructed psychomanteums, or oracles of the dead, where seekers could consult spirits of the deceased. I describe a modern attempt to recreate the psychomanteum. Like near-death experiences, visionary encounters in this modern psychomanteum are experienced as real and not as hallucinatory, and have profound personal aftereffects. This novel experimental technique may permit the scientific study of phenomena that previously occurred only spontaneously and under uncontrolled circumstances.

The wish once again to see and to be in the presence of a loved one who has died is among the most poignant and deep-seated of human desires. This wish is sometimes fulfilled in the form of visions or apparitions of the deceased. Many persons who have near-death experiences tell us that as they enter into a realm of light they are met by the spirits of relatives and friends who have previously died. Furthermore, several independent studies have established that an appreciable proportion of bereaved persons experience apparitions of the departed or vivid episodes during which they are overcome with a pervasive sense of the presence of the lost loved ones (Rees, 1975). All these kinds of

Raymond A. Moody, Jr., Ph.D., M.D., is a psychiatrist in private practice. Reprint requests should be addressed to Dr. Moody at 1215 Old Downing Mill Road, Anniston, AL 36201. 
encounters typically are convincing, even self-certifying; these persons usually are left with no doubt that their experiences were real.

Alas, although apparitions of the deceased are remarkably common, they do not lend themselves very readily to systematic study on other than a purely demographic and after-the-fact basis. For one can hardly count on being there just at the right moment to watch an apparitionwatcher watching an apparition, and to talk with him or her about it soon thereafter. And it is, we assume, impossible to precipitate them at will at a predetermined time and place. Yet, in the spring of 1990 several independent lines of research, thought, and experimentation converged in such a way as to suggest to me otherwise, and I conceived of a method by which, I believed, this could be done.

The very fact that apparitions of the deceased occur so frequently alerted me to the possibility of finding a way of encouraging them to take place under controlled circumstances of observation. It stands to reason that if we human beings are highly predisposed to such encounters anyway, a method might be devised to trigger them.

Among other advantages, this would make it possible to monitor persons experiencing apparitions of the departed while the episodes are in progress, and to interview them about the events immediately afterwards.

I had long been intrigued with the prospect of replicating near-death experiences. The popular fascination with this idea is reflected in the success of the recent Hollywood film Flatliners (Schumacher, 1990). However, no sane person would attempt to do this by the method sometimes imagined, viz., the induction of cardiac arrest in the hope that survivors of the procedure could bring back the latest dispatches from the other side.

One accepted way of proceeding when investigating a complex phenomenon is to analyze it into its component parts and to study some or each of these separately. Since meeting with departed loved ones is a feature common to many near-death experiences, demonstrating a way of calling forth the former phenomenon may well shed light on the latter.

For almost four years I had been experimenting with one form of facilitated visionary experience, specifically crystal or mirror visions. This research opened up a promising approach to the problem of enabling volunteer subjects to experience visionary reunions with lost loved ones.

Finally, while I was looking into some of the ways in which human beings have within institutional settings used altered states of consciousness for personal or social ends, I came across several accounts that raised the possibility that on a number of historical occasions 
methods were in use by which apparitions of the dead were made to appear to living persons.

Incredible as it may seem, for many centuries in ancient Greece there were institutions known as psychomanteums, or oracles of the dead, where people journeyed to consult with the spirits of the deceased. Accounts from those times make it quite clear that persons actually seemed to see and to be in direct communication with the departed during these visits.

Scholars have long tended to dismiss these reports by assuming that they resulted from fraud systematically perpetrated by the staff and attendants. However, in the course of my own research I arrived at quite a different conclusion. In trying to piece together the story of the oracles of the dead, and also in experimenting with various forms of visionary experience, I came to realize, I believe, how the spirits of the dead could well have been made to appear in at least one of the ancient psychomanteums.

This paper is a preliminary report on a highly successful attempt to recreate and to operate one of those fabled institutions of antiquity. I devised a procedure, based upon my research, that presupposed the creation of a special environment modeled on the oracle centers of the ancient world and also incorporating other ideas and principles upon which I shall elaborate later.

Carried out within that environment, the procedure has proven effective and reliable. A number of persons participating have experienced full-sized, appropriately moving, three-dimensional, aptly colored apparitions of departed persons. All subjects were psychologically normal adults who were in a waking state of awareness during the process. Some of the subjects reported complex communication with the apparition and most described having a convincing sense of the presence of the departed person during the interlude. All subjects so far have voiced their unequivocal personal convictions that the visitations were real.

Before I can adequately report these findings, however, I must first discuss certain ideas and principles woven into the design of this modern-day psychomanteum. I will begin in a way that may seem out of the way, by tracing some connections between the realm of paranormal phenomena and the world of play, humor and entertainment.

\section{Play and the Paranormal}

What is the nature of the human concern with the paranormal? That is, to what broad area of human endeavor is parapsychology, here defined broadly as organized human concern with the paranormal, 
most naturally related? I am asking here not what the conventionally established affiliations of the discipline are, nor what the conscious mind believes from habit or practice, but rather what the subconscious stirrings suggest.

Contemporary parapsychologists apparently think of themselves as scientists. Indeed, there is a widespread conventional notion to the effect that the activity or field of study known as parapsychology, a field that investigates purportedly paranormal phenomena, events, or abilities, either is or aspires to be subdiscipline of science. However, the controversy that in various forms has raged for centuries between proponents of scientific parapsychology and its scientific debunkers has thus far remained unproductive.

Furthermore, as it is now, although many people who become interested in the field do so as a response to personal grief, in some ways parapsychology has become abstract and intellectualized and seems almost to have surrendered its connection with the soul. So it may fail to console those who look to it at a time of personal loss and sorrow.

I would like to propose an alternate way of conceptualizing parapsychology, one that ultimately may prove more congruent with the human dimension and the human significance of phenomena deemed paranormal. Simply stated, this proposal is as follows: Parapsychology and the paranormal are related at least as strongly to play, humor, and entertainment as they are to scientific inquiry.

In making this claim I do not intend in any way to denigrate or to ridicule parapsychology. Despite our tendency to downplay their importance, humor, play, and entertainment are among the most significant human enterprises. The consolation they offer us is often indispensable in facing life. In addition, creative play is one important wellspring of discovery.

In my opinion, to proclaim parapsychology's interconnections with entertainment liberates the field in a new way, potentially enabling it more elegantly to fulfill a valuable role in human affairs. Various forms of entertainment, whether poetry, music, painting, sculpture, or drama, have long served to formulate, to clarify, or to advance the spiritual life of humankind. Some of the great classics of literature have spiritual themes or voice spiritual concerns.

In effect, parapsychology orchestrates what resemble or pass for certain methods or techniques of systematic inquiry in order to serve a spiritual end. Like forms of entertainment, parapsychology at its best can have a powerful uplifting effect, stirring profound emotions of awe, amazement, hope, and wonder, and helping us regain an appreciation of the basically uncanny nature of the universe in which we live. 
Parapsychology and entertainment share the distinguishing feature that they are defined in terms of their contrast with what is deemed ordinary reality, albeit in differing ways. In addition, many observations suggest that intuitive links exist between the realm of the paranormal and the worlds of entertainment, of humor, and of play. In fact, parapsychologists are probably most often seen or heard by the public on talk shows. The producers and hosts of these shows seek out parapsychologists with such frequency that the paranormal is one of the more common topics discussed in that type of forum.

Furthermore, for the overwhelming majority of people involved in studying the paranormal, it is a leisure-time activity. Legions of enthusiasts from every walk of life belong to clubs and other organizations devoted to the paranormal.

Fortune tellers' parlors can be found at amusement parks and beachside boardwalks. In some jurisdictions, fortune tellers, astrologers, and psychics are classified for purposes of licensure as recreation workers.

In their natural setting, various forms of divination that depend upon phenomena of interest to parapsychologists occur primarily as parlor games, such as ouija boards, table tapping, Tarot cards, and runes. Tarot even employs playing cards, like Old Maid or poker, while runes uses little game pieces, like Monopoly or Scrabble. Ouija boards are sold in toy stores. Dowsing with divining rods has game-like aspects, unless one is lost in the desert.

The principle I am trying to establish is preconsciously acknowledged in the naming of the "psychic fairs" taking place all around the country. Unconscious recognition of it may help explain why fundamentalists so abhor the paranormal; things that smack of play or humor are not their forte.

Some of the central concerns of parapsychology reside in puzzles deriving from the concept of personal identity. This concept is of overriding importance in evaluating claims about personal survival of bodily death, for example, or about reincarnation. Comedy, too, trades on this concept. Many comedies involve complications brought about by confounded identity, or by attempts by a character to hide or to disguise his or her true identity.

The basic subject matter of parapsychology is very often a standard form of story, anecdote, or narrative, such as a ghost story, an account of an apparently telepathic communication between friends, or a tale about an apparent premonition of an event that later took place. In this way, parapsychology can be seen to overlap with folklore, an aspect of human culture that plainly often serves to entertain.

The events and phenomena with which parapsychology is concerned 
lend themselves very naturally to presentation in dramatic form. It is often observed that the hysterical traits that make for good actresses also make for good psychics (Rogo, 1975).

The history of the study of the paranormal is replete with hoaxes. In their structure, hoaxes closely resemble and indeed sometimes are indistinguishable from practical jokes or pranks, which are unquestionably forms of humor. It is widely recognized that certain claims as to the occurrence of paranormal phenomena require testing not by scientists but rather by stage magicians. Magicians are clearly entertainers.

All of the above indicate that parapsychology can function as entertainment. What I want to propose is that parapsychology is a form of comedy, in that it attempts to assure or to reassure us that life has a happy ending. Further, since tragedy often is contrasted to comedy in that tragedy ends in death, parapsychology is the ultimate form of comedy in its attempts to establish that even death, the culmination of tragedy, has a happy ending, that death itself is no more than a doorway into another life.

Hence, the role of the skeptic or debunker with respect to parapsychology is not the same as the role of the rival in science. The scientist who attempts to refute or to call into question the claims of another scientist or to defend an alternate hypothesis is typically a person trained in the same or a closely allied field. The role of a debunker of claims to the paranormal is more like that of a heckler at the performance of a comedian, one who spoils the fun.

Or, the debunker assumes a role analogous to that of the moral critic of the theater. As Plato assured us that watching evil deeds portrayed on stage will predispose us to commit them, so the skeptics have warned that our society's flirtation with the transcendent will bring back the witchcraft trials and burnings.

One of the chronic grievances of the skeptics is that the media refuse to afford them equal time with the parapsychologists. I submit that an important reason for this is that the pronouncements of the skeptics have little or no entertainment value.

For the role of the true counterpart of the parapsychologist, I nominate the wonderful Lucian of Samosota. This Hellenistic writer was a creative genius. He saw artistic possibilities rather than subjects for dry academic exercises in the foibles of us, the devotees of the paranormal. All of the above reminds us that stories about the occurrence of paranormal phenomena are often met, as if by custom or convention, with derisive laughter. It is as though there exists an implicit social norm that permits one to express one's impression of claims about the paranormal by a form of contemptuous and dismissing laughter. 
For few if any other supposedly paranormal phenomena does convention condone derisive laughter quite as overtly as it does in the case of crystal gazing. Hence the stock theme of magazine cartoon caricature is the gypsy woman peering into her crystal ball. However, all this ridicule obscures the fact that an important and fascinating psychological phenomenon lies at the core of this venerable form of facilitated visionary experience.

\section{Crystal Visions}

Beginning in very remote times indeed, and independently in cultures all over the earth, human beings made an astonishing discovery: certain individuals see remarkable visions when gazing into the clear depth of a mirror, the still surface of a clear pond, or a crystal ball. These visions are eidetic; that is, they are projected into the visual space and are seen as though they are externally located. They are usually iridescently colored and three-dimensional and they often appear to move in a natural way, like the characters and scenes in a movie.

The imagery assumes an apparent size proportional to the size of the speculum, small images being seen in small speculums, and large images in large ones. The crystal gazer has a sense that the visions appear and proceed independently of his or her conscious volition.

Typically, their content falls into several categories: persons whom the gazer knows and others whom he or she does not recognize; panoramic scenes of preternatural beauty, such as lakes, forests, and mountain ranges; mini-dramas involving several persons in the same setting engaged in some activity; and forgotten incidents of the gazer's early life, vividly resurrected.

It is not too surprising that in the ages before the advent of depth psychology, crystal gazers tended to assume that they were seeing into the spirit world. Crystal gazing, as scrying, came to be used for divination: fortune telling, seeing events taking place at a great distance, locating lost objects, and criminal detection.

Divination by crystal gazing was practiced among the Ojibwa, Apaches, Cherokees, and other Native American groups. The chief oracle of Tibet used a magic scrying mirror to divine the future, and the cabinet ministers took his visions into account in directing state policy. In medieval Europe, specularii traveled from town to town telling fortunes by mirror gazing (Kieckhefer, 1989; Thomas, 1905).

Scrying figures prominently as a theme in literature. Fairy tales like "Snow White" (Grimm's Fairy Tales, 1944) and "Beauty and the 
Beast" (Opie and Opie, 1974) tell of magic mirrors. Scrying is also mentioned in Johann Wolfgang von Goethe's Faust (1960/1808-1832) and other versions of the life of the legendary Dr. Faustus. The fraudulent but lovable itinerant crystal gazer is a pivotal character in The Wonderful Wizard of $\mathrm{Oz}$ (Baum, 1982/1900).

Partly because of the association between crystal gazing and fortune telling, a kind of taboo about the subject has arisen among scholars. However, some scholars have ignored academic timidity and have studied crystal visions and done fascinating work. In the 16th century, John Dee made contributions in mathematics, navigation, theatrical special effects, and the study of antiquities. He began to study crystal gazing after an obsidian Aztec divination mirror came into his possession, and used crystal gazing in intelligence work he conducted for Queen Elizabeth I (Besterman, 1965).

I have been conducting research on crystal gazing since 1987, and up to now have demonstrated the technique to hundreds of people. I have directly observed more than 300 individuals as they were crystal gazing and afterward interviewed them about their experiences. Based upon this work, I conclude that crystal gazing can be a helpful technique in tapping into one's creative potential and an aid to selfunderstanding. Clients who are writers, poets, and painters have reported to me that after learning the technique they put it to use as a source of creative inspiration for their art. Several persons reported using it to their advantage in ferreting out conflictual issues and even in recovering repressed early trauma as a part of a process of psychotherapy.

I am now preparing an extended monograph fully reporting my research with crystal visions. For now, however, I will confine myself to reporting some surprising findings germane to this study. In the course of my investigation of crystal visions I have observed, both personally and in my subjects, four of the most curious phenomena of human consciousness I have ever encountered. Some are somewhat rare, even among habitual crystal gazers, but I am satisfied that subsequent researchers who are sufficiently patient will be able to document them all.

Journeys Into the Mirror World. It is popularly assumed that Lewis Carroll's Through the Looking Glass (1960/1871) is only a work of imaginative fiction. However, it is recorded that some shamans took journeys into the spirit world through their magic mirrors (Eliade, 1964), and thus far eleven persons who have experimented with mirror gazing at my facility, including myself, have undergone this particular 
adventure. After a variable period of time spent gazing at the various visions that appear in the mirror, the gazer may have the feeling that his or her center of consciousness goes into or through the mirror. At this point, the visionary world seems to surround or to encompass the mirror gazer. I find it more natural to describe my own experience with this by saying that suddenly I felt as though I was being sucked into the mirror. At any rate, the distinct impression during this time is that the visions are panoramic.

The Spirit in the Mirror. There are many legends and fairy tales in which a spirit is associated with a mirror, as in the case of the evil queen's magic mirror in "Snow White" (Grimm's Fairy Tales, 1944). Stories about the genie in the bottle or the lamp are further examples. Both historical and experiential research with mirror gazing reveal that these stories are based on an actual phenomenon of consciousness. Some people who regularly crystal gaze report that the same being routinely appears in the mirror or crystal on separate occasions. This entity acts like a moderator, directing the rest of the visionary show seen in the speculum.

Dee reported that a young girl/spirit whom he named "Madimi" appeared in his crystal again and again over a long period of time. Oswald Spengler recorded a case of a scryer who used his crystal to help clients locate lost objects. When the crystal was used, the first thing that became visible would be a figure of a particular man; the scryer would see this man in the crystal going through streets, into churches, etc., apparently in search of the lost object, presumably until it was found (Besterman, 1965).

Three of the persons with whom I have worked report this phenomenon. In one case, the figure who regularly appears is a young woman who seems to be in her twenties dressed in a medieval Middle Eastern costume. Some would say, of course, that such entities are dissociated aspects of the self of the crystal gazer. Whatever they represent, they come as a complete surprise to persons first encountering them.

The Emergence of Visions From the Mirror. Dee reported that from time to time Madimi would emerge from his crystal and cavort around his study. No scholar has taken his claim seriously, but my research shows it to be consistent with the phenomena of crystal visions. From time to time, subjects do report that the visions seem to leave the speculum and enter the surrounding environment. While gazing into a crystal ball, a graduate student of psychology reported he saw a coach appear as if at a great distance, being drawn along a country road by a 
team of horses. At one point, the coach seemed to emerge from the ball and pass in front of him; as it did, he was even able to see the clouds of dust being kicked up by the horses' feet. The coach turned, receded, entered again into the crystal, and disappeared into the distance.

A woman saw a bird flying around within the crystal; to her surprise, it flew out of the crystal, landed on the table on which the crystal ball was sitting, and appeared to be eating seeds.

I suspect that this phenomenon is the basis of stories about the genie getting out of the bottle or magic lamp. The rubbing of the lamp that causes the spirit to appear probably refers to the practice of polishing the metal surface of the lamp to provide a reflective surface in which the genie could then be seen by the gazer.

Incredibly, reports by Dee and others of phenomena that are the very stuff of a whole genre of legends, fairy tales, and superstitions, reports that have been set aside for centuries, dismissed as impossible, happen to be true. The genie can get out of the bottle now and then. Fortunately, though, nothing bad happens after that, and the genie goes back in eventually, at least so far.

Spontaneous Crystal Visions. Up to now, I have been primarily discussing phenomena that occur among persons who intentionally gaze into mirrors or crystals in hopes of seeing visions. However, crystal visions may also occur spontaneously, even among persons who have no familiarity with crystal gazing.

One woman related to me that one day when she happened to look up at the crystal chandelier in her home she was very much surprised to see an elaborate visionary scene acted out in one of the hanging crystals. A graduate student described to me how he suddenly saw a vision of his roommate's girlfriend, in her apartment across the country, appear in a large glass bottle sitting on a table about four feet away from him. The student's vision occurred immediately after his roommate had wondered aloud what his girlfriend was doing at the time.

A surprising number of spontaneous apparitions of the deceased are seen, wholly or in part, in mirrors or other reflective surfaces. A middle aged housewife related to me that a few months earlier she had seen an apparition of her grandmother in her home. She first saw her grandmother in a mirror at the end of a hallway. Then the apparition walked down the hallway and through an open doorway, vanishing into another room.

Anatole France related that his great-aunt saw a mirror vision of Maximilien-François de Robespierre dying, at what turned out to be 
approximately the same time he was in fact shot in the jaw. On the night of July 27, 1794, she looked into her mirror and shouted, "I see him, I see him. How pale he is. Blood is flowing from his mouth. His teeth and jaws are shattered. God be praised. The bloodthirsty wretch will drink no more blood but his own!" Then she cried out and fainted (Besterman, 1965, p. xvi).

On occasion, collective crystal or mirror visions of the deceased occur, that is, events in which more than one person simultaneously see an apparition of the same person. Ernest Bennett (1939, pp. 35-37) included one such case in his collection of accounts of apparitions:

December 3rd, 1885

On the 5th April 1875 my wife's father, Captain Towns, died at his residence, Cranbrook, Rose Bay, near Sydney, N.S. Wales. About six weeks after his death, my wife had occasion, one evening about 9 o'clock, to go to one of the bedrooms in the house. She was accompanied by a young lady, Miss Berthon, and as they entered the roomthe gas was burning all the time-they were amazed to see, reflected as it were on the polished surface of the wardrobe, the image of Captain Towns. It was barely half figure-the head, shoulders, and part of the arms only showing-in fact, it was like an ordinary medallion portrait, but life-size. The face appeared wan and pale, as it did before his death; and he wore a kind of grey flannel jacket, in which he had been accustomed to sleep. Surprised and half alarmed at what they saw, their first idea was that a portrait had been hung in the room and that what they saw was its reflection-but there was no picture of the kind.

Whilst they were looking and wondering, my wife's sister, Miss Towns, came into the room, and before either of the others had time to speak she exclaimed, "Good gracious! Do you see papa?" One of the housemaids happened to be passing downstairs at the moment, and she was called in, and asked if she saw anything, and her reply was, "Oh, Miss! the master." Graham-Captain Towns' old body servantwas then sent for, and he also immediately exclaimed "Oh, Lord save us! Mrs. Lett, it's the Captain!" The butler was called, and then Mrs. Crane, my wife's nurse, and they both said what they saw. Finally, Mrs. Towns was sent for and, seeing the apparition, she advanced towards it with her arm extended as if to touch it, and as she passed her hand over the panel of the wardrobe the figure gradually faded away, and never again appeared, though the room was regularly occupied for a long time after.

These are the simple facts of the case, and they admit of no doubt; no kind of intimation was given to any of the witnesses; the same question was put to each one as they came into the room, and the reply was given without hesitation by each. It was by the merest accident that I did not see the apparition. I was in the house at the time, but did not hear when I was called.

$$
\text { C. A. W. Lett }
$$


We, the undersigned, having read the above statement, certify that it is strictly accurate, as we both were witnesses of the apparition.

Sibbie Smyth (née Towns)

Mrs. Lett assures me that neither she nor her sister ever experienced an hallucination of the senses on any other occasion. She is positive that the recognition of the appearance on the part of each of the later witnesses was independent, and not due to any suggestion from the persons already in the room.

Any or all of these curious phenomena may be at the root of the old superstitious practice of covering up mirrors in a home where someone has died. It is believed that the custom originated in the fear that the spirit of the departed person might abduct the souls of living persons reflected in the mirror and take them away to the beyond.

This fear can occur in collective outbreaks. Children traumatized by the schoolyard mass murder in Stockton, California, developed a group phobia of the mirror in the school restroom. They believed that a harmful spirit inhabited the mirror and might come to get them.

It appears then both that visionary experience can be facilitated by the process of crystal or mirror gazing and that spontaneous apparitions of the departed are sometimes seen in mirrors. This suggested to me that mirror gazing might serve as a natural bridge between spontaneous and facilitated apparitions of the departed. There are indications that this or some other pathways were successfully used in historical times.

\section{Facilitated Apparitions of the Deceased: Historical, Anthropological, and Literary Evidence}

Clearly some of the ancients accepted that under certain circumstances one could see and even interact with spirits of the departed. This theme is sounded in myth: Orpheus was "allowed to summon the shade of his wife with the sound of his Thracian lyre" (Parke, 1967). In the Bible, we read that King Saul visited a woman of Endor and there saw and conversed with the spirit of Samuel, who issued a dire prediction as to Saul's fate (I Samuel 28:7-19).

The particular procedures employed in these instances are not clearly spelled out, however. By contrast, Homer provided a graphic account of a ceremony for calling up the dead. Following instructions 
from the sorceress Circe, Odysseus journeyed with his crew to an oracle center, taking with him a sacrificial ram and ewe:

... we beached our ship and put the animals ashore, and we walked along the shore until we came to the place which Circe had described.

Perimedes and Eurylochos held fast the victims, while I drew my sword and dug the pit, a cubit's length along and across ...

When I had made prayer and supplication to the company of the dead, I cut the victims' throats over the pit, and the red blood poured out. Then the souls of the dead who had passed away came up in a crowd from Erebos: young men and brides, old men who had suffered much, and tender maidens to whom sorrow was a new thing; others killed in battle, warriors clad in bloodstained armour. All this crowd gathered about the pit from every side, with a dreadful great noise, which made me pale with fear.

First came the soul of my comrade Elpenor, for he had not yet been buried in the earth. We had left his body at Circe's house, unmourned and unburied. ... I was moved with pity for him, and my tears fell as I asked him simply:

"Elpenor, how came you to the gloomy west? You have beaten our ship with only your feet to walk on!"

He answered with a groan:

"I was done for by bad luck and a mort of drink ... and my soul came down to Hades. Now I beseech you ... remember me, my prince, when you reach Aiaia, for I know you will touch there on your way back from Hades ....

I heard, and answered, "Be sure I will do this for you, my unhappy friend."

As we exchanged these sad words, I stood on one side holding my drawn sword over the blood, and my friend's phantom on the other, telling his long story.

Then came the soul of my dead mother, Anticleia, daughter of the brave Autolycos; she was alive when I left Ithaca on my voyage to sacred Ilion. My tears fell when I saw her, and I was moved with pity; but all the same, I would not let her come near the blood before I had asked my questions of Teiresias.

Then came the soul of Theban Teiresias, holding a golden rod. He knew me, and said, "What brings you here, unhappy man, away from the light of the sun, to visit this unpleasing place of the dead? Move back from the pit, hold off your sharp sword, that I may drink of the blood and tell you the truth."

As he spoke, I stept back from the pit,... "Ah well, Teiresias, ... here is something I want to ask, if you will explain it to me. I see over there the soul of my dead mother. She remains in silence near the blood, and she would not look at the face of her own son or say a word to him. Tell me, prince, how may she know me for what I am?"

He answered, "I will give you an easy rule to remember. If you let any one of the dead come near the blood, he will tell you what is true; if you refuse, he will go away." 
When he had said this, the soul of Prince Teiresias returned into the house of Hades, having uttered his oracles. But I stayed where I was until my mother came near and drank the red blood. At once she knew me, and made her meaning clear with lamentable words:

"My love, how did you come down to the cloudy gloom, and you alive? It is hard for the living to see this place. There are great rivers between, and terrible streams.... Are you on your way from Troy, have you been wandering about with ship and crew all this time? Haven't you ever been back to Ithaca, and seen your wife in your own house?"

I answered, "Dear mother, necessity has brought me to the house of Hades, for I had to consult the soul of Teiresias the Theban. I have not been near Achaia nor set foot in our country. I have been driven about incessantly in toil and trouble....

"But do tell me, really and truly, what was the cause of your death? how did you die? Was it a long disease? or did Artemis Archeress kill you with her gentle shafts?..."

[She replied] "... this is how I sickened and died. The Archeress did not shoot me in my own house with those gentle shafts that never miss; it was no disease that made me pine away: but I missed you so much, and your clever wit and your gay merry ways, and life was sweet no longer, so I died."

When I heard this, I longed to throw my arms round her neck. Three times I tried to embrace the ghost, three times it slipt through my hands like a shadow or a dream. A sharp pang pierced my heart, and I cried out straight from my heart to hers:

"Mother dear! Why don't you stay with me when I long to embrace you? Let us relieve our hearts, and have a good cry in each other's arms. Are you only a phantom which awful Persephoneia has sent to make me more unhappy than ever?"

My dear mother answered:

"Alas, alas, my child, most luckless creature on the face of the earth! Persephoneia is not deceiving you, she is the daughter of Zeus; but this is only what happens to mortals when one of us dies. As soon as the spirit leaves the white bones, the sinews no longer hold flesh and bones together-the blazing fire consumes them all; but the soul flits away fluttering like a dream. Make haste back to the light; but do not forget all this, tell it to your wife by and by." (Homer, 1946, pp. 124-128).

This hair-raising passage, which appears both impossible and incomprehensible, becomes clear and even plausible if we assume that it is an attempt to describe an archaic ritual the exact meaning of which had been forgotten by Homer's time.

I suggest that the function of the blood was to provide a reflective surface in which mirror visions of the deceased were seen. It is known that blood was used as a speculum for mirror gazing among the Maori of New Zealand (Thomas, 1905). A ritual of a Native American group is reminiscent of that Homer described: 
The Pawnees of the west of the United States seem to have had something akin to crystal gazing. When a badger was killed it was kept by the older people till night, and then skinned. The blood was poured into a bowl, and the children had to look at themselves in it by moonlight. If they saw themselves with grey hair it meant long life; if the picture was dark and indistinct the child would die of sickness; if no picture were seen at all the child would live, and be killed by the enemy.... The account ... seems obviously to relate to [mirror visions] and not ordinary reflections. (Thomas, 1905, pp. 43-44)

My interpretation clarifies what is otherwise an awkward point about Homer's text: Odysseus' peculiar bilocality. On the one hand, we are clearly told that he was standing beside a trench he had dug in the ground; on the other, both Tieresias and Odysseus' mother expressed surprise at seeing him there with them in the Underworld. I suggest that Odysseus was "going through the mirror" into another realm much as quite a few people have done already during the course of my research.

It is noteworthy that Homer placed this adventure near "the city of the Cimmerian people," close to the river Acheron, which was the site of the oracle of the dead at Ephyra. This elaborate subterranean complex consisted of corridors, winding labyrinthine passageways, small chambers, and a large hallway in which the apparitions were seen. In the latter area, Sotiris Dakaris, the archeologist who rediscovered the site in the late 1950's, found the remains of a huge bronze cauldron, with cogwheels scattered around it. This cauldron was surrounded by a balustrade that kept oracle-seekers from getting too close. Dakaris speculated that priests defrauded their clientele by squeezing into the cauldron and acting out the parts of the spirits the visitors expected to see (Parke, 1967; Vandenberg, 1982). Throughout history polished metal bowls, cups, and cauldrons have commonly been used as speculums for crystal gazing, as, apparently, was Joseph's silver cup alluded to in the Bible, "from which [he] drinks, which in fact he uses for divination" (Genesis 44:5). I am trying to contact Dakaris to find out whether this could have been a purpose of the vessel he found. If so, the visions of the dead could have been seen either in the polished external surface of the cauldron or, if it were filled with water, in the reflective surface of the liquid. The round shape would have made collective visions possible by allowing several persons to gaze into it simultaneously as they stood in a circle around the cauldron. In a speculum of large size, the apparitions could have appeared life size. Whether this turns out to have been the case or not, the possibility that it was so encouraged me 
to go forward with my attempt to recreate apparitions of the deceased by that method.

Perhaps several techniques were used at Ephyra, or different ones during different eras. Philipp Vandenberg (1982) wrote that seekers were essentially imprisoned underground for 29 days as they proceeded gradually through the various corridors and small rooms of the labyrinth. Many sacksful of small, burned bits of hashish were recovered from the floor. On the 29th day they were led into the apparition hall, which was approximately 50 feet long. Vandenberg suggested that in this room the flickering lamps cast eerie shadows on the walls, and that, under the influence of suggestions implanted by the priests, the seekers construed those shadows to be shades of the departed. After the apparition show was over, seekers were taken into an adjoining chamber where they were fumigated with sulfur, which by custom was used to purify anyone who had had contact with the dead. Then they were led directly outside into daylight and took a ritual bath in the river.

If this account is correct, then Plato's (1955) haunting allegory of the cave may be, on one of its many levels, a parody of the oracle at Ephyra. The two situations are parallel: persons imprisoned in a subterranean cavern being shown shadows cast on the walls by flickering flames, attendants bent on deceiving the prisoners into believing that the shadows are real, the captives at last liberated, led first up to the surface and then to a body of water.

The oracle of the dead at Ephyra was certainly functioning during Plato's lifetime; undoubtedly he would have known about it. Especially in his middle dialogues he showed superb artistry in lampooning many aspects of human life, including people in his own profession.

I am unable to determine whether or not Ephyra is the psychomanteum mentioned in Herodotus' account: the tyrannical King Periander sent emissaries to an oracle of the dead to consult the spirit of his wife, and they did in fact see her there. They failed to get the information the king wanted from her but what she did tell them was something only Periander could have known, proving to him the validity of the encounter (Parke, 1967).

In another time and place, Tungus shamans used copper mirrors to "place the spirits." In their language, the word for mirror was derived from the word for soul or spirit, and hence the mirror was thought of as a receptacle for the spirit. The shamans claimed to be able to see the spirits of deceased persons by looking into mirrors. At one time, the Malagasy of Madagascar evoked the spirits of the dead in the course of group ceremonies. It was common and accepted practice among these 
people to discuss their visions of and interactions with the departed. The shaman would begin one ritual by gazing into a mirror to establish contact with the spirits (Eliade, 1964).

Numerous allusions to rituals for making the spirits of the dead appear are found in medieval sources. Given the temper of those times it is not too surprising that records are sparse. It is known that books detailing such rituals were burned by the Inquisition.

What did survive is revealing. Procedures for conjuring up the spirits of the dead sometimes were included in books of medical material, raising the possibility that they were actually used by physicians. Young boys served as surrogate gazers; they saw spirits, and these entities divulged information that otherwise lay hidden (Kieckhefer, 1989).

In the eighteenth century, Count Alessandro di Cagliostro created an international sensation by demonstrating various apparently or allegedly paranormal talents (Dumas, 1967). He maintained an elaborate, exotically decorated studio in Paris where, numerous clients averred, spirits of the dead routinely appeared. It is plain that Cagliostro used mirror gazing. The people he selected as subjects were isolated behind a screen where they gazed into reflective objects. Mackay (1932) related that Cagliostro's spirits "appeared and conversed with him in crystals and under glass bells."

A related procedure was reported from Africa where it was part of an initiation ritual.

\begin{abstract}
Among the Nkomis the ... initiant is confined in a hut, at one end of which is a rude image of wood. Beneath the statue is deposited a packet containing the bones of someone long dead, and in front a looking-glass. The initiant is brought up to this mirror, and asked to describe what he sees, and as long as he replies "Nothing" his initiation is incomplete. When he answers that he sees the face of a man he is taken aside, and asked to describe him, and if he succeeds in describing the dead man whose bones are in the bundle he is at liberty to proceed to the next step.... [T]here is no possibility of fraud in the scrying part of the ceremony. The initiant has never seen the person whose bones lie beneath the statue, and yet his description is unmistakable. (Thomas, 1905, pp. 53-54).
\end{abstract}

Finally, to solidify the link between play and paranormal phenomena, there is a childhood parlor game in which spirits are conjured up in a mirror. I can find no scholarly documentation of this game, but I am assured of its existence by multiple informants. Numerous variations have been in circulation, but in all of them after some kind of 
ritual is conducted, the players gaze into a mirror, where a "ghost" appears.

If the art of making the dead appear was in fact practiced in earlier historical eras, why has this skill for all practical purposes disappeared? This is especially puzzling in light of the fact that so many people claim they long to see their departed loved ones.

One need not probe very deeply to solve this mystery. The absence of copyright and patent laws and of professional licensure in antiquity probably put the staff of psychomanteums under considerable economic pressure to keep their procedures secret. No doubt they also realized the emotional dangers inherent in permitting unsupervised lay persons to experiment with these techniques. There is evidence that they understood the importance of "processing" rituals to ease the client back into everyday reality, such as the fumigation and the ritual baths at Ephyra.

There was also institutionalized repression of such techniques, especially by religious authorities. Organized religious bodies with rigid ideologies have an interest in preventing persons under their control from seeking firsthand experience in the spiritual realm: what they experience there may embarrass the official doctrine. It is said that at a synod held by St. Patrick in the fifth century a canon anathematized any Christians who believed that a spirit can be seen in a mirror. They were to be excluded from any participation in church functions until they repented of this belief. In 1398, the specularii were condemned as Satanic by the Faculty of Theology in Paris (Kieckhefer, 1989).

However, organized religion is not alone in persecuting persons who try to raise the spirits of the dead. Such attempts have always been associated with charlatanism and other disreputable or officially disparaged conduct. As noted above, Dakaris accused the operators of the psychomanteum at Ephyra of fraud. By Herodotus' account, Periander, who consulted an oracle of the dead, was clearly a scoundrel (Parke, 1967; Vandenberg, 1982); disturbance played a central role in King Saul's life.

Persons who have in modern times attempted to make the dead appear have fared little better. Dee is reputed to have raised the spirit of a deceased person, although by what method is unclear. Early in his investigations of crystal gazing, Dee discovered that he was unable simultaneously to gaze into the mirror and to record his visions, and he resorted to employing a surrogate gazer. This brought him under the sway of the disreputable Edmund Kelley, an association that imperiled the scholarly Dee's work.

Cagliostro has been denounced as a mountebank and an impostor. 
There are claims that he only posed as royalty; his real name was Giuseppe Balsamo. He was brought to trial accused of being involved in a plot to purloin a diamond necklace belonging to the Queen.

However, it is quite possible to look at this litany of complaints from a very different perspective. Society has always dealt harshly with those who disturb consensus. Few principles of human life, whether cognitive or social, are as sacrosanct as the unbridgeable gap between the world of the living and the realm of the dead. Those who dare to trespass across that boundary invite the strictest scrutiny. Since few of us are saints, it would be easy to find problematic areas in the lives of almost anyone bent on making the spirits of the dead appear. By a question-begging circular argument, these could be used to cast aspersions on the practice itself. Sometimes, indeed, stories of the lives of persons who have made the attempt seem cast in a form intended to bring disfavor on the practice. A youth in the early 14th century, for example, a certain Benedict, became known for this skill. It is told that he was troubled by demons throughout the rest of his life. The moral, I presume, is that he was getting what he deserved (Kieckhefer, 1989).

In this light, some of the "evidence" adduced against practitioners of this art can be seen to be illusory. Part of the force of the alleged Biblical injunction against the practice derives from the fact that it was banned among the Jews. Yet it was Saul himself who had banned it, probably at the urging of priests who feared competition from nonJewish diviners. Herodotus' penchant for anecdotes about unsavory characters and circumstances is well known. He would have ignored stories about the many fine people who no doubt visited psychomanteums for benign or even commendable reasons.

It is quite possible that would-be practitioners unable to penetrate the secrecy of the oracles and learn how the spirits were made to appear resorted to fraudulent counterfeits. Hippolytus wrote:

But neither shall I be silent respecting that piece of knavery of these sorcerers, which consists in the divination by means of the cauldron. For, making a closed chamber, and anointing the ceiling with cyanus for present use, they introduce certain vessels of cyanus, and stretch them upwards. The cauldron, however, full of water, is placed in the middle of the ground; and the reflection of the cyanus falling upon it, presents the appearance of heaven. But the floor also has a certain concealed aperture, on which the cauldron is laid, having been previously supplied with a bottom of crystal, while itself is composed of stone. Underneath, however, unnoticed by the spectators, is a compartement, into which the accomplices assembling, appear invested with 
the figures of such gods and demons as the magician wishes to exhibit.

(Besterman, 1965, p. 45)

We can study the lives of historical practitioners so as to avoid their mistakes, thereby enhancing our chance of success. If the operators of the oracle of the dead at Ephyra cannot be conclusively cleared of allegations of fraud, it is partly because they maintained secrecy about their procedures. This should encourage us to make our results public by bringing our activities up onto the surface of the earth and out into the light of the sun. In a world increasingly saturated by the electronic media, attempting to suppress this knowledge would be futile anyway.

As for Cagliostro, much of the evidence against him is derived from the "confession" extracted from him after he fell into the clutches of the Inquisition! It does seem, though, that he was on a power trip. It is said that during sessions in which spirits appeared he maintained rigid control of the situation. He alone was allowed to converse with the spirits, to ask them questions, or to interpret their replies. All this served to focus Cagliostro's clients' attention on him; they were to regard him as having some unique and mysterious power or gift. His story should remind any contemporary practitioner to make sure that his or her clients realize that the ability to have visions is a power of their own. The practitioner is at most a facilitator. Dee's misfortunes should be sufficient to dissuade anyone from using surrogate crystal gazers.

Studying the historical record also provides us with another hint as to how one should go about causing spirits to appear. Specially constructed facilities and/or special settings were employed in the majority of instances we have surveyed. Thomas Carlyle even referred to Cagliostro's ornate studio as a "theater."

It must have been obvious to the operators of those historical facilities, as it has become obvious to me, that such emotionally laden and spiritually pregnant experiences should take place in an environment assembled in accordance with certain physical, psychological, and aesthetic principles, for two reasons. First, a person who undergoes a transformative spiritual experience should do so in a setting that is memorably pleasant and uplifting. Secondly, features of an environment can be arranged so as to precipitate altered states of awareness among persons wandering through it.

The Greeks built their oracle centers at impressive places. In classical times, psychomanteums were considered to be places where this 
world touched another. Even before Dakaris uncovered the oracle at Ephyra he had learned from local residents that it was popularly believed that the entrance to the Underworld was nearby. Today, we would call it a gateway to another dimension or a passageway to the other side.

At Ephyra the required interdimensional effect was achieved by harmonizing numerous known ways of altering consciousness within a single unified space. The subterranean location of the facility was in itself sufficient to create an uncanny atmosphere. Spiritual seekers have always sought out caves for their strange effects upon the psyche. Negotiating a labyrinth or maze can be mind-boggling, even in the clear light of day. Persons consulting the oracle were subjected to sensory deprivation, social isolation, and intoxication. As noted above, mirror gazing and pareidolia (seeing illusory figures in shadows, clouds, or other ambiguous stimuli) may also have been employed.

I decided to use the same multimodal approach in designing a contemporary psychomanteum, and to fashion it in such a way as to acknowledge the kinship between play and the paranormal, openly embracing the consequences of this reconceptualization.

\section{The Dr. John Dee Memorial Theater of the Mind}

In the spring of 1990 , having realized that I needed a space in which to conduct further investigations of crystal gazing, I located an appropriate building and began to prepare the facility. At the Theater of the Mind, a variety of elements, including art, music, play, relaxation, creative activity, physical exercise, nature, hypnogogic states, perceptual illusions, intellectual stimulation, and humor, are blended to create an atmosphere conducive to altered states of consciousness. It is at once a theater, a temple, a fortune teller's parlor, a spiritual retreat center, an art museum, a school, a library, and a funhouse. In addition, it resurrects some of the long-forgotten institutions of the ancient world: the Greek oracle, the dream incubation temples of Asklepios, the museion (where people went to seek inspiration from the Muses), and of course the psychomanteum. The overall purposes of the Theater of the Mind are education, entertainment, and spiritual growth through altered states of awareness.

My strategy has been to incorporate within this environment as many as possible of the factors known to ease the transition into altered states of awareness, as follows. 


\section{Nature}

It is well known that the wonders of nature can precipitate mystical and other spiritual experiences. Something deep within human beings is very powerfully moved by natural beauty.

The Theater is housed in a small gristmill beside a creek in a secluded rural area near Choccolocco, Alabama. Numerous wild creatures live nearby, and forest lands are abundant in the area. This location enables clients to take walks and to commune with nature during their stay, and to be directly exposed to natural beauty.

\section{Alterations in the Sense of Time}

Persons who experience altered states of consciousness often report that during these episodes their sense of time is altered or distorted. Persons attending programs at the Theater of the Mind are asked not to wear watches. No clocks are in sight and the timepieces that are present harken back to earlier eras. For example, a sundial in the yard subtly reminds clients of a more primitive method of reckoning time. Certain sessions, such as those involving "psychic readings" through crystal gazing, are timed by an hourglass.

The decor in the entire building is anachronistic. The use of antique furniture in a building itself built in $\mathbf{1 8 3 9}$ has the effect of propelling one back to an earlier era. An extensive library of nineteenth century stereoscopic cards provides a window into a time long past.

\section{Art}

It is clear that art can induce altered states of consciousness. "The Stendahl syndrome" refers to the experience in certain types of individual of psychotic-like episodes upon being exposed to great art. Also, it is well known that from time to time madmen attack great art. The Nightwatch, the Pieta, and the David, among others, have all suffered assaults by disturbed individuals during recent years. Finally, the concert pianist Erik Pigani directly related to me how he and a considerable number of renowned performing artists personally interviewed by him have undergone profound spiritual experiences while performing great musical masterpieces (Pigani, 1989).

An effort has been made to harness this phenomenon at the Theater of the Mind. Provocative and unusual art is displayed throughout the 
building. Art books are placed prominently in waiting areas to encourage clients to peruse them.

Art and decorations have been chosen not solely for their beauty but also to induce surprise, shock, or feelings of incongruity. Generally, things are not matched in the Theater, since matching items provides a sense of sameness, stability, and predictability. For example, each piece of china used during meals is different, each interesting in its own way. This has the effect of keeping the client's mind preoccupied with novel stimuli and in a constant state of wonder.

\section{Intellectual Stimulation}

Historically, the pursuit of knowledge has been an important channel through which human beings have sought spiritual direction and enlightenment. The Theater of the Mind maintains an extensive library on altered states of consciousness, the paranormal, and spirituality, and clients are encouraged to browse among these books. In addition, almost all of our programs include lectures and other didactic presentations on these topics. The intellectual aspects of our programs are fully integrated with the other components to encourage the attitude that serious scholarship, too, can be fun.

\section{Humor}

Humor is obviously strongly associated with creativity. Mirth itself might well be classified as an altered state of consciousness; it is a delightful feeling almost like an intoxicant in its effect. Laughter directly relaxes the skeletal muscles of the body. The incongruities of humor often lead to new insights and to self-understanding.

Some of the art present at the Theater is humorous in tone, and laughter is allowed and appreciated as an integral part of our programs. We plan to build a library of comedies on videocassettes, and we maintain a collection of comic books and other humorous volumes.

\section{Play}

Play is associated primarily with childhood and many adults seem to have forgotten how to play. This trait can be part of a generally rigid personality style. Individuals of this type are highly serious-minded in their approach to life. 
Such persons often have difficulty entering altered states of awareness. Play is used liberally at the Theater of the Mind to undermine those defenses.

A room on the first floor is used for initial get-acquainted sessions. Subsequently, clients can wait here for their turns with other activities. This room is designed to evoke unconscious associations with childhood playgrounds. Clients sit on swings suspended from exposed beams and cushions on the floor. Toys that appeal to adults as well as children are liberally supplied, such as kaleidoscopes, puzzles, magic tricks, colorful picture books, and curiosities of various kinds.

The purpose of this room is implicitly to encourage playfulness and relaxation, so that clients will suspend adult norms and open themselves up to possibilities other than those of the everyday world.

\section{Drama}

Great playwrights have always plumbed the depths of the psyche and the spirit of humankind. Sublime drama evokes profound emotions; we are moved to tears and to laughter. Great drama can even shape our attitudes to persons and events in the ordinary world. The importance of drama in our lives is illustrated by the fact that exceptional or prominent actors and actresses are idolized, and even made the object of cult-like adoration, as in the case of Rudolph Valentino, James Dean, Marilyn Monroe, or Elvis Presley.

Celebrities play an important role in contemporary society. Modern humans spend a large percentage of their waking hours attending to information and images propagated by the media. People respond as they do to celebrities, I believe, in part because celebrities constitute a link between the world that appears to us through the media and the world of everyday reality. Because they are in principle capable of appearing "in person" they serve to reassure us, on an unconscious level at least, of the "reality" of the electronically generated world in which we spend an increasingly large proportion of our lives.

I have made an attempt to put this transdimensional quality of drama and of charismatic thespians into action at the Theater of the Mind. From the 1920s through the 1950 s, movie theaters usually had wooden marquee boxes for posters advertising present or coming attractions. A client donated a gilded, ornate marquee rescued from an old theater about to be demolished. It stands in the downstairs playroom/waiting area beside the doorway into the other sections of the Theater. Effigies and other representations of celebrities who have themselves become icons, such as Laurel and Hardy and Humphrey 
Bogart, are displayed at selected spots to take advantage of their symbolic force as interdimensional beings.

\section{Mirrors}

Mirrors are located at prominent places throughout the building, for several reasons. They symbolize the quest for self-understanding: soulsearching and reflection. Mirrors are a frequent focus of superstition and hence their presence sets up reverberations in a primitive level of the mind. A set of funhouse mirrors allows clients to experience distortion of the body image, further loosening their attachment to the ordinary view of reality. Finally, mirrors are used in ongoing programs involving crystal visions.

\section{Others}

The roles of music and relaxation, both of which are integral parts of our programs, in inducing altered states of awareness are too well known to require comment. In the future, we hope to add an art therapist to our staff in order to help clients tap into their creative processes. One of our staff members is constructing an isolation tank so we can add sensory deprivation to the modalities currently being used.

The intended effect of the interplay of all these elements is not to coerce participants into an attitude of frivolity or hilarity but rather to create an inner psychic doorway to other dimensions of the mind by allowing them safely to surrender some of their inhibitions. Thus, it came as a great relief to hear one of the first persons attending a program at the Theater of the Mind describe his experience as "like stepping through into another world. It makes you feel that time is unreal."

Preliminary results strongly suggest that the basic concept is indeed viable. Persons attending the Theater have regularly reported striking manifestations of phenomena that traditionally have been called paranormal. Yet all this has been achieved within the context of an approach that makes no claims whatsoever about the ontological status of these experiences. Clients are allowed to make their own judgments as to the reality of their experiences.

It is within this environment that an increasing number of persons have taken voyages to the further reaches of consciousness, and even beyond the boundary that separates the living from the dead. 


\section{The Oracle of the Dead at Choccolocco}

A room on the second floor of the Theater of the Mind was set aside for use as an apparition chamber. At one end of the room, a mirror 48" high by 42 " wide was mounted on the wall so that its bottom edge is 32 " above the floor. A comfortable easy chair was prepared by removing its legs so that the top of the head rest is 34 " above the floor. The chair was placed on the floor about 3' in front of and facing the mirror. Since the head rest of the chair is inclined very slightly backwards, persons sitting in the chair and gazing into the mirror from that position are unable to see their own reflections. A small stained glass lamp with a twenty-five-watt bulb was placed directly behind the chair. The whole area was surrounded by a curtain of black velvet reaching from ceiling to floor, suspended from above by a framework of plastic tubing painted black. The area of the wall between the bottom edge of the mirror and the floor was also covered with black velvet.

When the lights in the room are turned off, except the lamp inside the booth, outside light is excluded by blinds and thick window curtains, providing an adequate environment for mirror gazing. It was tested and found to be excellent by a number of persons who had already experienced crystal visions in previous workshops and courses.

Potential volunteer subjects were selected from persons well known to me, on the basis of these criteria. They are all mature persons who are interested in human consciousness and are emotionally stable, inquisitive, and articulate. A number are older graduate students of psychology who had returned to an academic environment to pursue their studies after variable periods of time spent in other walks of life. Some are counselors, psychologists, or professionals in other fields.

Persons who have occult ideologies were excluded from the project so as to eliminate one layer of complication when analyzing the results. Also, persons known to have suffered from emotional or mental disorders were excluded so as to lessen the likelihood that the procedure might precipitate untoward reactions.

The project was explained in detail to all potential volunteers contacted. Persons who elected to participate were asked to choose one deceased person to whom they had been close and whom they would like to see again. They were asked to select a few mementoes, objects that had been owned by the deceased person and that they strongly and poignantly associated with that person. (This was added to the original plan after it was suggested by several among the first group of potential subjects contacted.) Each volunteer selected a future date upon which he or she would come to the Theater of the Mind to attempt to see the lost loved one. 
Each volunteer was asked to arrive at the Theater at $10 \mathrm{AM}$ on the appointed day, bringing the momentoes. As the day unfolded, the subject was guided through the following procedure. The subject and I took a leisurely three- or four-mile walk in the countryside during which we explored the subject's motivation for attempting to see the departed person. The subject was told that there was no guarantee that an apparition would be seen and was prepared for this possibility by emphasizing that there is no pressure to have any kind of experience at all.

After the walk, we ate a light lunch of soups, salad, fruit, and fruit juices. During the afternoon, the subject and I discussed at great length and in detail the person who had died and the relationship that had existed between the two of them. We explored such areas as the kind of person the deceased had been, and his or her appearance, habits, and personality. The subject's important and touching memories of times and events in the life of the deceased were brought to light and discussed in great detail. Both the subject and I held, examined, and discussed the significance of the mementos the subject had brought.

Just before they were to enter the mirror booth, about two thirds of the subjects were placed for 45 minutes in a bed designed and built by a staff member of the Theater of the Mind. It is a comfortable recliner equipped with several speakers arranged to play music through the subjects' body by bone conduction. This apparatus induces a profound state of relaxation and, in most, altered states of awareness.

Around dusk, each subject was escorted into the mirror gazing booth, the lamp inside was turned on, and all other light in the room was eliminated. Subjects were instructed to gaze deeply into the mirror and to relax, waiting for the deceased person to appear. They were told to stay in the booth as long as they wished; no time limits were suggested and subjects were asked not to wear watches while in the booth.

An attendant sat in the next room during this whole time, prepared to render any needed assistance. When the subject emerged, an extended processing session began during which the subject discussed what had happened and was allowed fully to ventilate his or her feelings and discuss the whole experience until we reached closure. The subject then left the psychomanteum.

Before the first subject had been guided through the exercise, I assumed that only a small percentage of the subjects, at most one out of ten, would experience an apparition under the conditions of the exercise, and that for those who did the experience would be limited to seeing, in the mirror, a vision of the departed person they had been prepared to see. I assumed that all subjects would be dubious about the 
reality of the encounter and would say that they were unsure as to whether it was real or just "in their minds." And I assumed that the experience would be self-limited, confined conveniently to the environs of the psychomanteum and within the span of time allotted. The subjects would come to the Theater and be guided through the procedure, as a result of which they would either see on apparition of the chosen person or else see no one at all. Following the processing session, they would go home, leaving the realm of the shades behind at the psychomanteum.

None of those assumptions proved true, and the picture that has emerged from this project is dramatically different from what I had initially imagined. Because this is so I must at this point explain that although for convenience I am using words like "study," "experiments," and "investigation" to describe this project, I am fully aware that what I have done is not a scientific study. Rather, it is a systematically conducted demonstration that it is possible to duplicate the common human experience of seeing apparitions of the deceased. Accordingly, the numbers and percentages I will be giving are to be taken solely as a rough index of the relative ease with which such experiences can be elicited, at least under the special conditions I have already described.

Thus far, 12 of the 25 persons who have been guided through the entire procedure, and four other persons who were subjected to briefer versions of the preparation, have experienced apparitions. Nine of the persons who experienced apparitions were male and seven female. They ranged in age from 22 to 74 years, and all were articulate and intelligent. They included two counselors, a psychologist, an ophthalmologist, a radiologist, two social workers, a businessman, two journalists, four students of psychology, and two authors (including myself).

Never once during the planning stage of this experiment did it enter my mind that the apparitions might talk as well as appear; yet that is precisely what happened in six of the sixteen apparitional encounters. In these cases, complex quasi-communications were reported to take place between subjects and apparitions. These ranged from a few words of reassurance and love to lengthy, involved, interactive communication.

A journalist in her early $60 \mathrm{~s}$, a well-respected editor of a large newspaper, came to the psychomanteum hoping to see her son who had committed suicide some months earlier. When he appeared, he told her that he was fine and that he loved her. During another session, a man in his mid-30s saw his deceased mother who, much in the manner of Anticleia in Homer's account, expressed surprise and curiosity as to 
how her son had come to where she was. One woman, a 44 year old counselor, described lengthy conversations with her deceased father.

In several of the experiences in which no "verbal" exchanges took place, there was, nevertheless, communication of some other kind. One man reported that the apparition of his mother acknowledged his presence and conveyed to him nonverbally that she felt the woman to whom he had recently become engaged was good for him and that she approved. This man had been very close to his mother, and this reflected a concern that had been on his mind. Another man, a psychologist, saw two of his cousins; he felt that they acknowledged his presence during the encounter.

Another surprise was that not every subject met the person he or she had expected to see. A businessman in his 70s spent a long day with me preparing to see his father; it was his departed business partner who showed up instead. A woman tried to see her husband but it was her father who came to her. I sought a meeting with my maternal grandmother, but it was my father's mother who appeared to me.

Subjects so far have been unanimous in asserting that what took place was completely real. When I asked a smiling 55 year old ophthalmologist what his judgment was, whether he felt his experience was a projection of his own mind, he said with emphasis, "Oh, no! I saw my mother!" A woman assured me with complete confidence and equanimity that she had indeed been with her deceased father. A journalist insisted that he had in fact seen and visited with his father during his session in the mirror booth.

Thirteen of the subjects described a compelling sense of the presence of their lost loved ones during these encounters, a feeling they voiced in such phrases as "I know he was there" or "I felt his presence, definitely, when I was in the booth."

The apparitions do not confine themselves to the mirror, or even to the psychomanteum. One man was startled to find the apparitions of three of his departed relatives actually emerge from the mirror and surround him as he sat in the mirror gazing booth. He reached up as if to touch them, wondering at first if we were trying to deceive him by a simple masquerade, whereupon his hand seemed to go right through the apparitions, much to his surprise. A woman felt the presence of her grandfather so palpably that she felt him comfort her in an embrace.

In three cases the apparitions occurred after the subject had left the psychomanteum. The forty-four year old counselor came in hopes of seeing her husband. She experienced no visions during her session in the psychomanteum. However, shortly after she returned home she experienced two separate apparitions of her father, during which she 
had lengthy conversations with him. The journalist whose son appeared to her while she was in the psychomanteum spent that night in a motel. After she had already locked the door and was preparing to go to sleep she was surprised to find her son again standing in her motel room. My grandmother appeared to me at a location far from the psychomanteum; when I first saw her, she simply walked into the room in which I was sitting.

Exactly why this delayed effect sometimes takes place is unknown. The counselor felt that going through the preparatory exercises and the mirror gazing session had "opened (her) up" in some way she found difficult to describe.

In two of the cases, the subject experienced some initial difficulty recognizing the apparition. When the journalist's son appeared in her motel room she at first concluded that an interloper had forced his way into her room. After her initial shock of surprise, and as she established communication with the person, she realized it was her son. My first thought when I saw an unknown person come into the room in which I was sitting was that she was somehow familiar to me, in an unusual way. It was only after I talked with her for a minute or so that I recognized her as my paternal grandmother.

Some awkward interpersonal dilemmas can arise from these meetings. A radiologist was surprised to encounter his adolescent nephew who had committed suicide a decade earlier. The child instructed his uncle to tell his mother, the physician's sister, that he was fine, that everything was all right. The radiologist felt completely sure that he had actually been in the presence of his nephew. However, he was concerned about how his sister would react to this news. As he was leaving the psychomanteum, he had tentatively decided to begin by characterizing it to her as a very realistic dream although he felt not quite honest about doing so.

All these encounters, however astounding they might be, seem quite natural while they are going on. They do not seem in any way weird, spooky, or strange. They are certainly not frightening.

In every case thus far, it is the relationship between the departed person and the subject that seems to be the centerpiece of the whole encounter. No one so far has thought to ask any theoretical or metaphysical questions during the exchanges. No one has asked, for example, what "the other side" is like, or how the departed was able to appear. Once the episodes begin, subjects tend to focus on the immediacy of the presence of the departed persons and simply to relate to them and enjoy their presence. Every subject so far has intimated, in one way or another, that for him or her the encounter was experienced 
primarily as a healing of the relationship with that person. The woman whose grandfather hugged her, for example, explained that she had been devastated by his death and she thanked us profusely for creating "a place where people can come and be healed."

It is convenient for me at this point to give a brief description of my own experience, but I do so to make a point I believe would be agreed to by all, or certainly almost all, of the subjects in this study. It is very difficult to put this experience into language; I am at a loss to explain some of it in words. Yet, I have no doubt whatsoever that I was in the presence of my deceased grandmother for an extended period and did in fact converse with her at length. At first, as I said, I did not recognize this person, though she immediately seemed somehow familiar. She looked somewhat as she had while alive on the earth, but appeared younger than she had been even when I was born. When I recognized her as my grandmother and confronted her with this fact, she immediately acknowledged it and began to use the nickname she alone had used for me when I was a child. She talked with me about events only my grandmother and I knew. She imparted to me certain very personal information about my early life that has been quite important and revealing.

I understand, as I am sure everyone who has had such an experience must understand, that others who have not must assume that we are the victims of hallucinations. I have experimented with several altered states of awareness including hypnogogia and lucid dreams and have had hallucinations following surgery. What I experienced, whatever it was, was in no way related to these other experiences. It was so completely coherent with the reality that I have experienced all my life that were I to discount it then so would I be compelled to discount the rest of my life, too, as hallucinatory.

Of course, in saying this I am not trying to persuade anyone else of the validity of my encounter. I fully realize that words are not capable of persuading anyone about such things if he or she has not had a personal experience. I am only trying to convey a sense of how completely real these experiences can be to the persons undergoing them.

I might add that the relationship between me and my paternal grandmother had been rather difficult while she was alive. Yet, our meeting enabled us to smooth things over. I now see her humor and appreciate her as a person in a brand new way. I look forward to meeting her again when I make my transition.

Finally, although curiosity was my initial motivation in beginning this study, I rapidly came to realize that one must never lose sight of the relevance of grief and bereavement to such investigations. When I 
explained the project to the first few potential volunteers, I specified that they were to choose someone who had died and with whom they had no outstanding unresolved issues, as I wanted to avoid contaminating my experiment by introducing unsettling emotional material. Several reacted with dismay and protested that they wanted to see people with whom they had unfinished business. Some pointed out that things are never really completely in balance between any two people anyway, living or dead. Indeed, I have come to see in the course of this research that it is impossible to conduct the work of a psychomanteum without remaining attuned to the relevance of grief in human life.

Literally, the term "psychomanteum" implies that the spirits of the dead are summoned as a means of divination, to ask them questions about the future or about other hidden knowledge. Hence, purists will quibble that this facility is not a psychomanteum, since the purpose for which people come to the Theater of the Mind is not to arouse the dead for divination. Rather, they come to explore aspects of themselves of which they are not yet fully aware and in hopes of satisfying a longing for the company of those whom they have lost to death. But whatever the differences in intention and articulated policy between those ancient institutions and this contemporary one, I suspect that they converge in their day to day operation.

Plutarch (1961) related the touching story of a Elysius, who was obsessed with the thought that perhaps his young son who had died had been poisoned. In his torment Elysius went to a psychomanteum in what is now southern Italy, which apparently employed dream incubation. After conducting prescribed rituals, Elysius fell asleep and had a vision in which both his deceased father and his son appeared to him and reassured him that the death was due to natural causes.

Hence, in whatever mode the Greeks may have expressed their longing and their grief, they were no different from us. Elysius plainly was seeking resolution of his grief. I am sure that then as now many come seeking not knowledge but solace in the psychomanteum.

\section{Discussion}

If in the course of subsequent research facilitated apparitions of the departed prove indistinguishable from spontaneous ones, then a common phenomenon which has for a long time been regarded by many as paranormal has at last become available for monitoring under controlled circumstances. Electroencephalographic and other determina- 
tions of brain activity during ongoing visions of the deceased will become possible.

Subjects could be interviewed immediately after or conceivably even during the event. This would obviate one of the classic objections to the possibility of studying apparitions scientifically: since appearances of the departed are always reported after the fact, they are subject to unconscious elaboration and distortion by the memory.

Some scholars maintain that the belief in life after death had its origin in dreams and waking apparitions and of the departed. It may now be possible to put this claim to a test, since all subjects thus far were fully convinced of the reality of their visitations. We can thereby observe the formation and development of paranormal beliefs in normal subjects.

Individuals in the throes of bereavement often become preoccupied with images of the deceased. They may carry around and gaze at photographs of the lost loved one, for example. Insofar as spontaneous apparitions of the departed are considered to be an aspect of the human response to the loss of a significant other, the study of facilitated apparitions may yield insight into the psychology of bereavement.

Also, the present study illustrates how psychology enhances our understanding of certain perplexing historical institutions, practices, or personages that might otherwise remain incomprehensible. For example, today most people assume that shamans either were mentally ill, were charlatans, or possessed some extraordinary faculty most of us lack. I have already noted that shamans claimed to be able to take voyages into the spirit world through their magic mirrors and to see the spirits of the dead there. The present study demonstrates that both of those abilities exist in normal persons. First-hand experience with mirror gazing makes the inner worlds of those ancient tribal practitioners accessible to us in a new way.

There is intrinsic value in self-understanding. Seeing apparitions of the departed is a faculty of the human mind, one that has left its mark on history and literature and that continues to influence contemporary culture. Hence, bringing the operation of this faculty within the sphere of conscious determination is enlightening in itself and may result in a richer understanding of the capacities and limits of the mind. By their very occurrence, these encounters bear witness to the wonder of consciousness, being in themselves direct revelations of the vast outer reaches within.

Many persons who experience apparitions of deceased loved ones relate that the episodes result in an alleviation or even a resolution of 
their grief. Subjects who encountered apparitions in the present study experienced the events primarily as healings of the relationships with the deceased persons. It is conceivable that in the future therapeutic techniques might be derived from investigations like this one.

All of the above seem to be legitimate extensions of this work. I would caution, however, against trying to conduct research into this fascinating phenomenon with the aim of collecting evidence for life after death. Some have imagined that subjects might be instructed to quiz the shades in order to gather hidden knowledge that could be objectively verified: "Grandpa said that if you walk ten paces north of the old oak tree in the back yard and dig down four feet you'll find an old tin box," for example.

But even if such information were to be obtained and corroborated, it would be subject to alternate explanations: "Perhaps when the subject was six months old, he or she was lying in a crib beneath an open window while, just outside, Grandpa was mumbling to himself, busily digging a hole," etc.

Moreover, the emphasis reflected in such a proposal is not true to the emotional and spiritual impact visions of the departed have upon persons experiencing them. Cognitive or theoretical concerns tended not to arise during these visitations, and this was so even among subjects who were highly intellectualized in their overall approach to life. It is the relationship between the subject and the departed person that comes to the fore during these interludes. This would complicate attempts to use this procedure for purely abstract and theoretical purposes.

I plan to continue this research along three lines. I am in the process of locating further historical material pertaining to the classical oracles of the dead and plan to visit some of those sites. Also, I intend to do a study in which persons who previously have experienced spontaneous apparitions of the departed either alone or as part of a neardeath experience will be guided through this procedure. Those who do experience apparitions under those conditions will be asked to compare the facilitated experiences with their spontaneous ones.

I plan also to attempt to facilitate collective apparitions among several persons at once, all of whom have known one and the same deceased person. Spontaneous collective apparitions of the departed have been documented; this gives me confidence that this line of investigation will eventually come to fruition. Success in this endeavor may tell us something about the dynamics of collective visionary phenomena in general. 
I hope that the publication of this paper will encourage other investigators to explore this most puzzling territory, but I want to issue some caveats for those who elect to do so.

First, attempts to replicate this phenomenon on a solo basis should be avoided. Although no participants have suffered untoward reactions in the course of this exercise, it is obvious that these encounters stir up strong feelings. Common sense dictates that one undertake this adventure only with a competent and grounded support person or guide readily available and to allow an adequate period for ventilation and processing afterward.

I also want to re-emphasize that in my judgment the environment in which this work is conducted is a major determinant of its overall success, for reasons already indicated. Each setting needs to be assembled in a careful, indeed I would say a loving way. It would be selfdefeating to design each facility as an exact replica of the Theater of the Mind; I suspect that mere copyists would not be as successful. Each operator of a psychomanteum must exercise creative artistry to achieve both the effect of an intersection between dimensions and an overall atmosphere of warmth and serenity.

I would forewarn anyone who wants to delve into this area to be prepared to encounter angry reactions, even hostility, from professional colleagues and lay persons alike. This came as a complete surprise to me. Although people often commend me for the courage they believe it must have taken to look into near-death experiences and sympathize with me for the scorn they guess must have been heaped upon me by skeptical scientists and physicians, such imaginings are overblown. As much as I am enamored with the role of the martyr, I must confess that I didn't suffer that much persecution for my earlier research.

However, it has been different in the case of my present work. When I told one psychologist about my plans to conduct this study, he exclaimed, "There goes your career!" Another person to whom I was close even forbade me to speak of the subject in her presence. Yet another, a psychiatrist, had an even more ominous response. I was diagnosed with severe hypothyroidism in 1985 and since that time have been maintained on a fixed dosage of thyroid hormone. In December, 1991, for reasons still unclear, the long-established dosage proved too much, and I became hyperthyroid. When attempts were made to correct this, my hormone level dropped below normal again, and I became delirious.

A month earlier, a university had invited me to make a presentation on this project at a forthcoming symposium. When I was admitted to 
the hospital I had in my possession a written summary of my presentation. I needed a copy of this made so that I could get my son to fax it to the university for their printed brochure announcing the event.

After having interviewed me for a few minutes, the psychiatrist volunteered to make a copy of it for me and when he returned from having done so remarked that he had taken the liberty to make a copy for himself as well. He said that it showed that I had "gone off the deep end" (his words) and, despite my known history of hypothyroidism, he made the diagnosis of manic-depressive illness and prescribed lithium!

I refused the lithium and the symptoms cleared within a few days as my hormone level returned to normal. As for my summary, the university printed it as I had written it, and several months later the advertised presentation was very well received.

Part of the difference in the reception accorded my previous and present research may be a function of locale. During the time of my early work with near-death experiences I was living in fairly large, fairly cosmopolitan cities that counted among their citizenry numerous published authors exploring exciting topics. While I was formulating the ideas for my current research project, I was living in a small provincial town.

The reception historically accorded attempts to cause the spirits of the dead to appear is one indication that some of this difference is real. The strongest negative reactions to such studies can be expected from certain religious fundamentalists who voice their old refrain that this is the work of Satan.

Personally, I have become largely inured to these cavils, but potential researchers need to be forewarned.

Such, then, are some of the pitfalls to be avoided by those who embark upon calling forth the spirits of the dead. Such explorers will also come upon a number of intriguing conceptual hurdles.

There may well be those who will respond to this study by congratulating me for rediscovering hypnosis and suggestion. Although this paper is no place for an extended discussion of either concept, I submit that both terms are too vague or ill-defined to be of use in the present context. "Hypnosis" seems to refer not just to one but rather to a number of distinct altered states of awareness. I am the only subject so far who has extensive experience with hypnosis; in addition to having used hypnosis clinically with many clients I am also an excellent hypnotic subject. I have firsthand experience with very deep trance states and many unusual hypnotic phenomena, including posthypnotic suggestion and negative hallucinations. I can attest that my 
own visit with my grandmother was radically different from anything I have experienced during my two decades of familiarity with hypnosis. As to "suggestion," the fact that some subjects in the study saw someone other than the person they set out to see illustrates the difficulty in explaining these happenings solely in terms of that concept.

At any rate, the theoretical issues with which I am most concerned do not have to do with the causation of these encounters per se. The claim that unusual, supposedly paranormal, experiences are the result of hypnosis or suggestion is typically advanced to contravene the hypothesis that the experiences are genuinely paranormal, that they really do manifest life after death, for example.

But such hypotheses are not at present amenable to rational proof or refutation. The far more interesting questions, in that they are answerable, have to do with whether the facilitated apparitions can be used as an experimental model for spontaneously occurring ones. If so, then this work may be a genuine advance in knowledge.

I could make similar remarks about attempts to explain these apparitions as hypnogogic phenomena. When I began my research with crystal gazing, I assumed that the images were hypnogogic. However, the results reported here would require a considerable expansion and reformulation of the concept of hypnogogia before they could be accommodated within that framework.

This work has nothing to do with mediumship or seances. Mediums claim to possess some extraordinary capacity that enables them to contact the spirits of the dead on behalf of their clients and to convey messages back and forth. The client presumably must accept that such a talent exists and that the particular medium possesses it. Mediumship provides at best a secondhand encounter, mediated, as the term "medium" implies, through a third party. The procedure in this study is quite different: clients are enabled to have their own, firsthand apparitional encounters and are allowed to make their own assessments as to their reality.

Some might protest that possibly the living could be conjured up, too, or fairies and dinosaurs, Thor and Little Orphan Annie or even Santa himself. But all this is still beside the point that by the use of this method a common, important, and little-understood form of human experience-apparitions of the departed-may be re-created in an environment within which it can be subjected to thoroughgoing study and analysis.

Despite the fact that this study may have a number of more immedi- 
ate and tangible implications, it is my fond hope that cumulatively and in the long run such projects might have a positive influence on the collective spiritual condition of humankind. We live in a society which has for a long time defined knowledge in such a way that ego-aware attentive, reflective, analytic consciousness has come to be regarded as the only path to truth. Vaclav Havel, in a profoundly moving speech to Congress, voiced his opinion that at this point we can be saved from self-destruction only by a worldwide revolution in consciousness, a sort of spiritual and visionary Jeffersonianism. It seems that we are becoming more and more a nation of self-avowed visionaries. As this trend continues there will be more investigations into altered states of awareness. Let us hope that some day those studies will help enable us to secure the blessings of love, life, liberty, and the pursuit of happiness for all people everywhere.

But for now what we can say is limited. The capacity to evoke convincing apparitions of deceased persons among the living has been conclusively demonstrated, but by precisely what process or agency they take place is not yet known to us.

\section{References}

Baum, L. F. (1982). The wonderful Wizard of Oz. New York, NY: New American Library. (Original work published 1900)

Bennett, E. (1939). Apparitions and haunted houses. London, England: Faber and Faber. Besterman, T. (1965). Crystal-gazing. New York, NY: University Books.

Grimm's fairy tales. (1944). New York, NY: Pantheon.

Carroll, L. (1960). Through the looking glass. In The annotated Alice (M. Gardner, Ed.).

New York, NY: World Publishing. (Original work published 1871)

Dumas, F. R. (1967). Cagliostro (E. Abbott, Trans.). London, England: George Allen and Unwin.

Eliade, M. (1964). Shamanism: Archaic techniques of ecstasy. Princeton, NJ: Princeton University Press.

Goethe, J. W. von. (1960). Faust (P. Wayne, Trans). New York, NY: Viking Penguin. (Original work published 1808-1832)

Homer. (1946). The Odyssey (W. H. D. Rouse, Trans.). New York, NY: Mentor.

Kieckhefer, R. (1989). Magic in the Middle Ages. Cambridge, England: Cambridge University Press.

Mackay, C. (1932). Extraordinary popular delusions and the madness of crowds. New York, NY: Farrar, Straus and Giroux.

Opie, I., and Opie, P. (1974). The classic fairy tales. London, England: Oxford University Press.

Parke, H. W. (1967). Greek oracles. London, England: Hutchinson University Library. Pigani, E. (1989). Channels. Paris, France: L'Age du Verseau.

Plato, (1955). The republic (B. Jowett, Trans.). New York, NY: Random House.

Plutarch. (1961). Consolation addressed to Apollonius. New York, NY: Viking Penguin.

Rees, D. W. (1975). The bereaved and their hallucinations. In Schoenberg, B., Gerber, I., 
Wiener, A., Kutscher, A. H., Peretz, D., and Carr, A. (Eds.), Bereavement: Its psychosocial aspects. New York, NY: Columbia University Press.

Rogo, D. S. (1975). Parapsychology: A century of inquiry. New York, NY: Dell. Schumacher, J. (Director). Flatliners [Film]. Hollywood, CA: Columbia.

Thomas, N. (1905). Crystal gazing. New York, NY: Dodge.

Vandenberg, P. (1982). The mystery of the oracles. New York, NY: Macmillan.

Virgil. (1983). The Aeneid (R. Fitzgerald, Trans.). New York, NY: Random House. 